\title{
Novel Approach to Plasma Facing Materials in Nuclear Fusion Reactors
}

\author{
V. Livramento ${ }^{\mathrm{a}}$, J.B. Correia ${ }^{\mathrm{a}}$, D. Nunes ${ }^{\mathrm{b}}$, P.A. Carvalho ${ }^{\mathrm{c}}$, H. Fernandes ${ }^{\mathrm{c}}$, \\ C. Silva ${ }^{c}$, K. Hanada ${ }^{\mathrm{d}}$, N. Shohoji ${ }^{\mathrm{a}}$, E. Osawa ${ }^{\mathrm{e}}$ \\ aINET1, Departamento de Materiais e Tecnologias de Produção, Estrada do Paço do Lumiar, 1649-038 \\ Lisboa, Portugal \\ ${ }^{b}$ Associação Euratom/IST, Departamento de Engenharia de Materiais, Instituto Superior Técnico, Av. \\ Rovisco Pais, 1049-001 Lisboa, Portugal \\ 'Associação Euratom/IST, Centro de Fusão Nuclear, Instituto Superior Técnico, Av. Rovisco Pais, \\ 1049-001 Lisboa, Portugal \\ ${ }^{d}$ National Institute of Advanced Industrial Science and Technology (AIST), 1-2-1 Namiki, Tsukuba, \\ Ibaraki 305-8564, Japan \\ ${ }^{e}$ NanoCarbon Research Institute, Ltd., AREC, Fac. Textile Sci. Technol., Shinshu University, 3-15-1 \\ Tokita, Ueda, Nagano, 386-8567, Japan
}

\begin{abstract}
A novel material design in nuclear fusion reactors is proposed based on W-nDiamond nanostructured composites. Generally, a microstructure refined to the nanometer scale improves the mechanical strength due to modification of plasticity mechanisms. Moreover, highly specific grainboundary area raises the number of sites for annihilation of radiation induced defects. However, the low thermal stability of fine-grained and nanostructured materials demands the presence of particles at the grain boundaries that can delay coarsening by a pinning effect. As a result, the concept of a composite is promising in the field of nanostructured materials. The hardness of diamond renders nanodiamond dispersions excellent reinforcing and stabilization candidates and, in addition, diamond has extremely high thermal conductivity. Consequently, W-nDiamond nanocomposites are promising candidates for thermally stable first-wall materials. The proposed design involves the production of $\mathrm{W} / \mathrm{W}-\mathrm{nDiamond} / \mathrm{W}-\mathrm{Cu} / \mathrm{Cu}$ layered castellations. The $\mathrm{W}, \mathrm{W}-\mathrm{nDiamond}$ and W-Cu layers are produced by mechanical alloying followed by a consolidation route that combines hot rolling with spark plasma sintering (SPS). Layer welding is achieved by spark plasma sintering. The present work describes the mechanical alloying processsing and consolidation route used to produce W-nDiamond composites, as well as microstructural features and mechanical properties of the material produced. Long term plasma exposure experiments are planned at ISTTOK and at FTU (Frascati).
\end{abstract}

Keywords: mechanical alloying, nanoparticles, composite materials.

\section{INTRODUCTION}

There has been growing interest in the nuclear fusion as an energetic option for the future, to meet the needs of a growing world population. This energy source can be used to produce great quantities of energy (in particular electricity), without emission of gases to the atmosphere, and the fuel resources are very abundant and can be easily found anywhere over the Earth (the fossil fuels cause climate change and are finite). However one of the major obstacles to build at a commercial fusion reactor is the lack of suitable first wall materials that will allow competitive operating temperatures as well as minimization of component replacement during the reactor's life. A high thermal conductivity, thermal stability and room temperature ductility are requested

CP996, Plasma and Fusion Science, edited by C. Varandas and C. Silva

(C) 2008 American Institute of Physics 978-0-7354-0515-8/08/\$23.00 
for the reactor's plasma facing materials [1, 2]. Nanocomposites are conventionally produced by mechanical alloying and powder metallurgy processing. These materials usually have better mechanical performance (including hardness). In the present research nano-diamond particles were used as reinforcement component for Tungsten (W). Tungsten has the highest resistance to irradiation (high flux of neutrons and gamma-ray) and highest melting point. $W$ also has a great corrosion resistance and the highest tensile strength at elevated temperature of all metals [3]. The neutron irradiation of $\mathrm{W}$ does not produce armful radioactive elements with a long decay periodes, due to its high resistance to erosion. The atoms of $\mathrm{W}$ are not easily incorporated into the plasma, and therefore, do not contaminate it. The hardness of nanodiamond in addition with its high thermal conductivity, makes $\mathrm{W}$-nD nanocomposite a good option for one of the layers in the first wall of a fusion nuclear reactor. But one challenge concerning these two elements is the strong affinity of carbon towards $\mathrm{W}$. Therefore, there is the possibility of forming carbides instead of having the nanodiamond phase well dispersed in tungsten. The processing used must avoid the equilibrium reaction of carbide formation and preserve nanodiamond, consequentially improving the thermal conductivity. Using mechanical alloying, the reinforcement (nanodiamond) can be mixed and dispersed in the matrix (W). High energy milling of $\mathrm{W}$-nanoDiamond powders under argon atmosphere was performed in order to develop a suitable material for the first wall of nuclear fusion reactors. Powder consolidation using SPS and rolling were also aimed at preserving the $\mathrm{nD}$ structure in bulk parts.

\section{EXPERIMENTAL PROCEDURES}

During this research several powder samples with nominal compositions of $\mathrm{W}-$ $40 \%$ at $\mathrm{nD}$ were produced. The nanodiamond powders were prepared by stirred-media milling as previously reported $[4,5]$. After evaporating water from the colloid in an oven heated at $65^{\circ} \mathrm{C}$ for $24 \mathrm{~h}$ to remove $99 \%$ of water, visible agglomerates of $\mathrm{nD}$ particles that have diameters of 2-3 $\mu \mathrm{m}$ were obtained and the agglomerate powder was used for mechanical alloying. Pure elemental $W$ was used as the matrix $(99,95 \%$; median particle size $1 \mu \mathrm{m}$ ).

The millings were carried out in a Retsch PM400 planetary ball mill, using WC balls with a diameter of $10 \mathrm{~mm}$ in $250 \mathrm{ml}$ WC containers. The mill was operated at a rotation speed of $200 \mathrm{rpm}$ during 2 and 4 hours. The batch milling charge, was constituted by $19.17 \mathrm{~g}$ of $\mathrm{W}$ and $0.83 \mathrm{~g}$ of $\mathrm{nD}$. In order to prevent oxidation of the powders, the containers were first evacuated and then back-filled with Argon. All the powder batches were characterised by X-ray diffraction (XRD), optical microscopy, field emission scanning electron microscopy (SEM) with energy dispersive X-ray spectroscopy analysis (EDS), and microhardness measurements (performed under a load of $25 \mathrm{~g}$ for $15 \mathrm{~s}$ for the as-milled powders and $50 \mathrm{~g}$ for $15 \mathrm{~s}$, for the consolidated materials), as previously described [6]. The milled powders were encapsulated in stainless steel cans and consolidated by hot-rolling at $800^{\circ} \mathrm{C}$ or by Spark Plasma Sintering (SPS) at $800^{\circ} \mathrm{C}$ and also using both techniques of consolidation (first the powders were consolidated by SPS and then by hot-rolling). The nanocomposite W$\mathrm{nD}$ milled for $4 \mathrm{~h}$ at $200 \mathrm{rpm}$ and consolidated by hot-rolling was inserted into the 
ISTTOK edge plasma $(a-r=1-2 \mathrm{~cm})$ and exposed to both cleaning discharges and plasma pulses. The plasma characteristics were: Te Ti $=10-40 \mathrm{eV}, \mathrm{n}=0.5-2 \times 10^{18} \mathrm{~m}^{-3}$ and $\mathrm{q}_{/ /}=0.1-1 \mathrm{MW} / \mathrm{m}^{2}$. The powder deposited on the $\mathrm{W}-\mathrm{nD}$ sample was $2.5 \mathrm{~W}$ with an effective exposure time of $1200 \mathrm{~s}$. The processing parameters of the materials produced are shown in table 1, including the milling times for mechanical alloyed (MA) powders, the temperatures and the type of consolidations of all samples and the respective microhardness values. Metallographic preparation, revealed a much higher degree of densification in the SPS consolidated sample.

\begin{tabular}{|c|c|c|c|}
\hline Batch & $\begin{array}{l}\text { Milling } \\
\text { Time [h] }\end{array}$ & $\begin{array}{c}\text { R. Speed } \\
{[\mathrm{rpm}]}\end{array}$ & Microhardness [HV] \\
\hline $\mathrm{W}-\mathrm{nD}-2 \mathrm{H}$ & 2 & 200 & $1558.0 \pm 282.8$ \\
\hline \multirow{2}{*}{ W-nD-4H } & \multirow[t]{2}{*}{4} & \multirow{2}{*}{200} & $\begin{array}{c}\text { Homogeneous particles (bright) } \\
2427.5 \pm 290.2 \\
\end{array}$ \\
\hline & & & $\begin{array}{l}\text { Heterogeneous and darker particles } \\
1461.0 \pm 205.9\end{array}$ \\
\hline $\begin{array}{c}\text { W-nD-4H SPS } \\
800^{\circ} \mathrm{C} \\
\end{array}$ & 4 & 200 & $2796 \pm 271.2 .6$ \\
\hline \multirow{2}{*}{$\begin{array}{l}\mathrm{W}-\mathrm{nD}-4 \mathrm{H} \text { Hot- } \\
\text { rolling } 800^{\circ} \mathrm{C}\end{array}$} & \multirow{2}{*}{4} & \multirow{2}{*}{200} & $\begin{array}{c}\text { Homogeneous particles (bright) } \\
2780,6 \pm 553,2\end{array}$ \\
\hline & & & $\begin{array}{l}\text { Heterogeneous and darker particles } \\
1444,0 \pm 417,7\end{array}$ \\
\hline \multirow{2}{*}{$\begin{array}{l}\mathrm{W}-\mathrm{nD}-4 \mathrm{H} \\
\text { SPS and Hot- } \\
\text { rolling } 800^{\circ} \mathrm{C}\end{array}$} & \multirow[t]{2}{*}{4} & \multirow{2}{*}{200} & $\begin{array}{c}\text { Homogeneous particles (bright) } \\
2706,5 \pm 282,9\end{array}$ \\
\hline & & & $\begin{array}{l}\text { Heterogeneous and darker particles } \\
\qquad 1433,1 \pm 335,5\end{array}$ \\
\hline
\end{tabular}

TABLE 1. Processing parameters and respectively microhardness values.

\section{RESULTS AND DISCUSSION}

Figure 1 shows $\mathrm{X}$-ray diffraction patterns of the as-milled $\mathrm{W}+\mathrm{nD}$ powders and the consolidated samples.

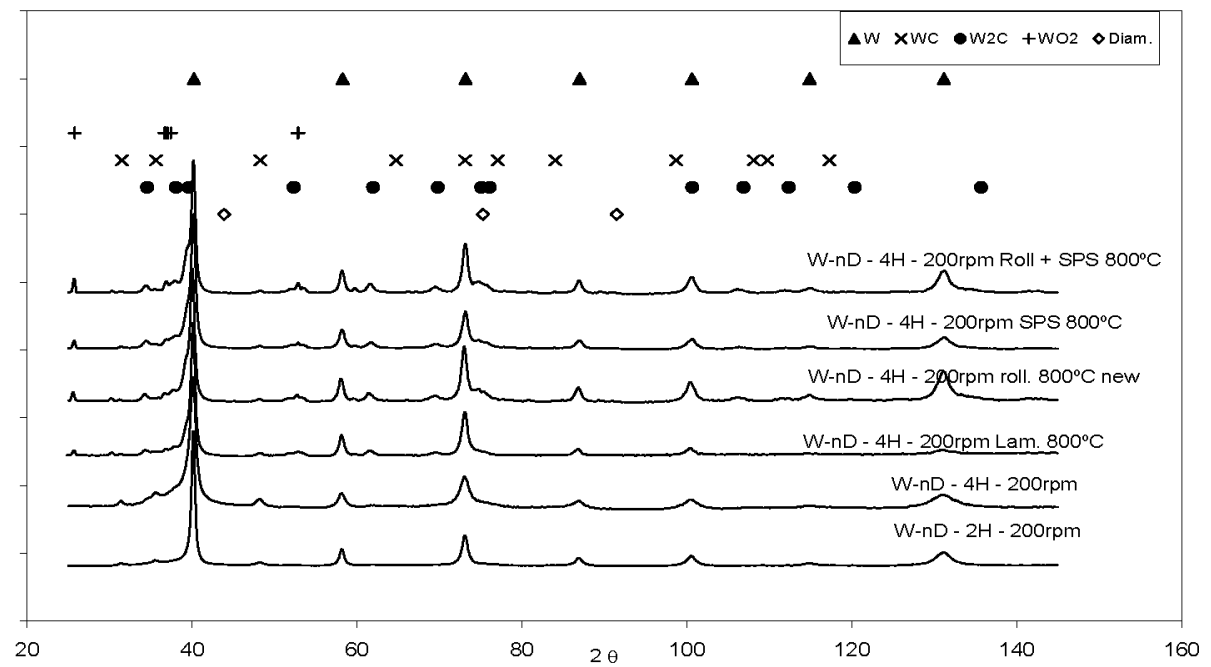

FIGURE 1. XRD patterns for $\mathrm{W}+\mathrm{nD}$ powders milled for 2 and 4 hours and consolidated samples. 
The major phase present after MA and after consolidation was thus $\mathrm{W}$, minor reflections of $\mathrm{WO} 2, \mathrm{WC}$ and $\mathrm{W} 2 \mathrm{C}$ were also identified.

The oxides and carbides are less evident in the diffractogram of the powder milled for $2 \mathrm{~h}$, but this mixture is not so homogeneous and well distributed comparing with the powders milled for $4 \mathrm{~h}$, as it is possible to observe in the SEM pictures (figure 2).

For this reason and comparing the microhardness values (table I), powders with a milling time of $4 \mathrm{~h}$ were always chosen for consolidation. The diffraction peaks became broader with the increasing of milling time, reflecting a decreasing crystallite size. Conversely the peaks after consolidation are sharper, reflecting grain coarsening.
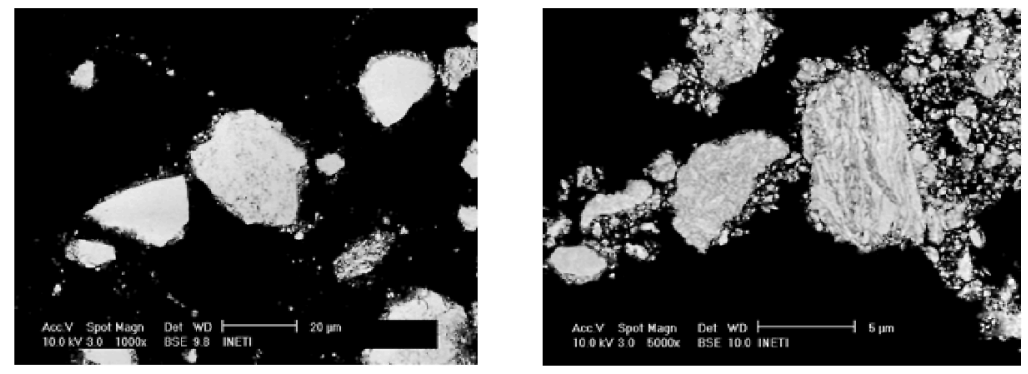

FIGURE 2. SEM/BSE pictures of $\mathrm{W}+\mathrm{nD}$ powders milled for $2 \mathrm{~h}$ and $4 \mathrm{~h}$ respectively (200rmp).

An example of SEM/BSE (back scattered electron) images of the $\mathrm{W}+\mathrm{nD}$ powders subjected to MA for $4 \mathrm{~h}$ and consolidated by hot-rolling at $800^{\circ} \mathrm{C}$ are shown in figure 3 . Notice that the darker areas have more oxygen than the brighter areas, showing that the darker areas are richer in oxides, probably owing to the tungsten oxide present is the pristine powders.

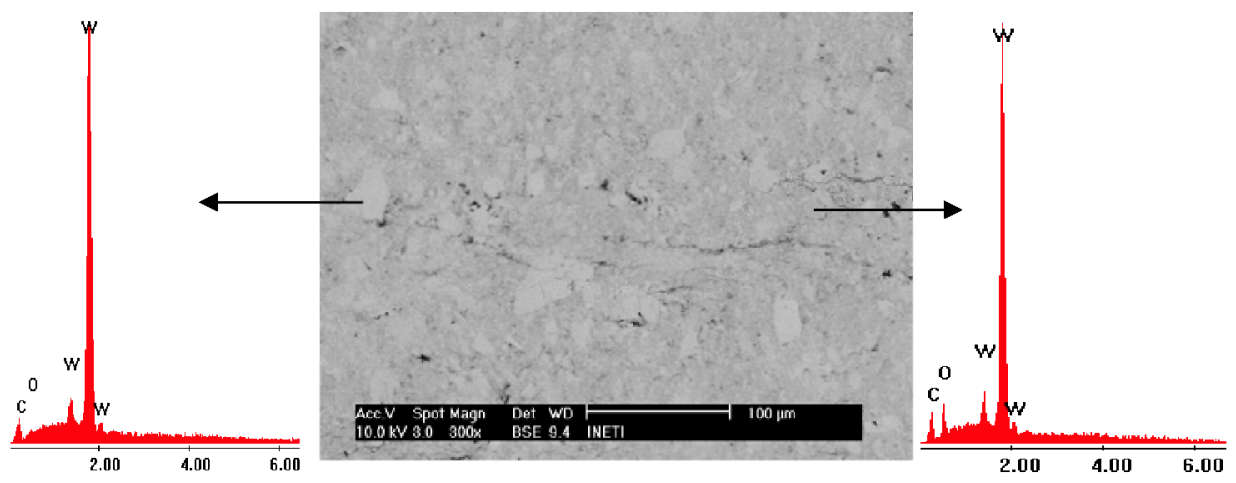

FIGURE 3. SEM/BSE image of $\mathrm{W}+\mathrm{nD}$ subjected to $\mathrm{MA}(4 \mathrm{~h}$ at $200 \mathrm{rpm})$ and rolling at $800^{\circ} \mathrm{C}$ and respectively EDS chemical analysis.

The microstructural features of the consolidated powders are essentially identical to those of the starting powders when observed with SEM, figure 4. No evidence of recrystallization was found. 

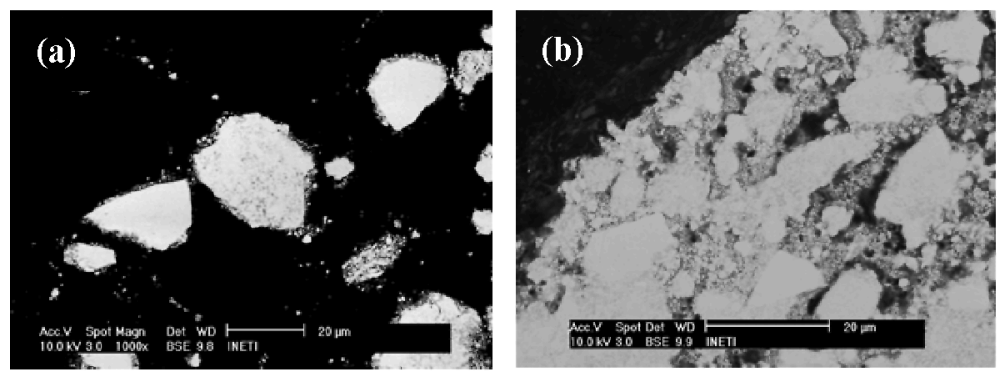

FIGURE 4. (a) SEM/BSE image of $W+\mathrm{nD}$ as milled powders ( $4 \mathrm{~h}$ at $200 \mathrm{rpm}$ ) and (b) SEM/BSE image of $\mathrm{W}+\mathrm{nD}$ consolidated by $\mathrm{SPS}$ at $800^{\circ} \mathrm{C}$.

Figure 5 presents the first results obtained with the $\mathrm{W}-\mathrm{nD}$ material consolidated by hot-rolling at $800^{\circ} \mathrm{C}$ and exposed to the edge plasma in ISTTOK.

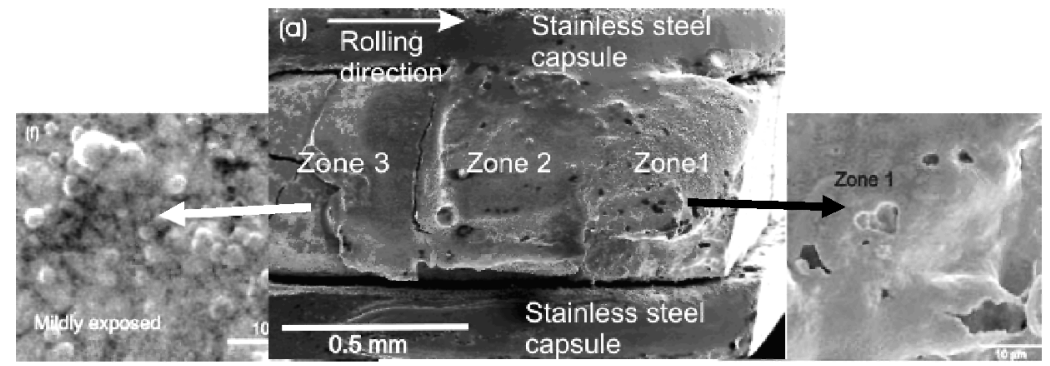

FIGURE 5. W-nD subjected to MA (4 h at $200 \mathrm{rpm}$ ) and rolling at $800^{\circ} \mathrm{C}$ and exposed to the edge plasma.

Zone 1 shows signs of intense evaporation, and subsequently modification of structure. However, below $1 \mathrm{~mm}$ the nanoparticles of nanodiamond were essentially preserved. The exposure of SPS consolidated material is under way at ISTTOK and at FTU.

\section{CONCLUSIONS}

The present results show that high-energy milling at $200 \mathrm{rpm}$ followed by SPS at $800^{\circ} \mathrm{C}$ yielded the best $\mathrm{W}-\mathrm{nD}$ nanocomposite consolidate with satisfactory high density. By the chosen processing parameters, bulk specimens were obtained without undesired carbide formation.

Short milling time of only 2 and 4 hours provided a favourable condition for the least contamination of ball material in the mechanical alloying.

Exposure to plasma of rolled $\mathrm{W}-\mathrm{nD}$ produced surface modification of structure. However, below $1 \mathrm{~mm}$ the material presents non-exposed characteristics, since the $\mathrm{W}$ $\mathrm{nD}$ nanocomposite was essentially preserved. 


\section{REFERENCES}

1. M. Ubeyli, S. Yalcm, J. Fusion Energy 25, 2006, pp. 197.

2. http://www.iter.org/ THE ITER PROJECT, Fusion Energy (2006),

3. Robert K. Herrick, "DC/AC Circuits and Electronics: Principles \& Applications", Delmar Learning for Purdue University (2003).

4. M.V. Korobov, N.V. Avramenko, A.G. Bogachev, N.V. Rozhkova, E. Ösawa E.J. Phys. Chem. C 111, 2007, pp. 7330-7334.

5. Williams, O.; Douheret, O.; Daenen, M.; Haenen, K.; Ösawa, E.; Takahashi, M. Chem. Phys. Lett. $445,255-258$ (2007).

6. V. Livramento, J.B. Correia, N. Shohoji, E. Ösawa, Diam. Rel. Mater. 16, 202 (2007). 